\title{
Implementation of access and benefit-sharing measures has consequences for classical biological control of weeds
}

\author{
Luciana Silvestri - Alejandro Sosa - Fernando Mc Kay - Marcelo Diniz Vitorino • \\ Martin Hill • Costas Zachariades · Stephen Hight • Philip Weyl • \\ David Smith • Djamila Djeddour • Peter G. Mason
}

Received: 12 August 2019/Accepted: 5 December 2019/Published online: 14 December 2019

(C) The Author(s) 2019

\begin{abstract}
The Convention on Biological Diversity and the Nagoya Protocol establish that genetic resources shall be accessed only upon the existence of prior informed consent of the country that provides those resources and that benefits arising from their utilization shall be shared. Pursuant to both agreements several countries have adopted regulations on access and benefit-sharing. These regulations have created a challenging obstacle to classical biological
\end{abstract}

Handling Editor: S. Raghu

Electronic supplementary material The online version of this article (https://doi.org/10.1007/s10526-019-09988-4) contains supplementary material, which is available to authorized users.

L. Silvestri

Consejo Nacional de Investigaciones Científicas y

Técnicas, Av. Ruiz Leal s/n, Ciudad de Mendoza,

Argentina

e-mail: 1silvestri@mendoza-conicet.gob.ar

A. Sosa · F. Mc Kay

Fundación para el Estudio de Especies Invasivas, Bolívar 1559, Hurlingham, Buenos Aires, Argentina

A. Sosa

Consejo Nacional de Investigaciones Científicas y

Técnicas, Godoy Cruz 2290, C1425FQB CABA,

Argentina

M. D. Vitorino

Universidade Regional de Blumenau, Rua São Paulo,

Blumenau 3250, Brazil control of weeds. This paper reviews the experiences of Argentina, Brazil, South Africa, the USA, Canada and $\mathrm{CABI}$ in implementing access and benefit-sharing regulations and the implications these measures have on the effective and efficient access, exchange and utilization of biological control agents. We conclude that policy makers should be made aware of the key role biological control plays for agriculture and the environment and they are encouraged to develop tailored access and benefit-sharing legal frameworks that facilitate biological control research and implementation.

Keywords Nagoya protocol - Classical biological control of weeds · Biodiversity · Access and benefit-

M. Hill

Centre for Biological Control, Rhodes University,

P.O. Box 94, Grahamstown 6140, South Africa

C. Zachariades

Plant Health and Protection, Agricultural Research

Council, Private Bag X6006, Hilton 3245, South Africa

C. Zachariades

School of Life Sciences, University of KwaZulu-Natal, Private Bag X01, Scottsville 3209, South Africa

S. Hight

Agricultural Research Service, USDA, 6383 Mahan

Drive, Tallahassee, FL 32308, USA

P. Weyl

CABI, Rue des Grillons1, 2800 Delémont, Switzerland 
sharing · Convention on biological diversity $\cdot$ Genetic resources

\section{Introduction}

Classical biological control of weeds utilizes one or more natural enemies (biological control agents), primarily insects, mites or pathogens, to suppress populations of a weed that is causing damage to economically and/or ecologically important species. The introduction of natural enemies from the area of origin of an invasive alien weed depends on access to host plants and their natural enemies in the region where the weed species naturally occurs (i.e. is native, often as a non-weedy species). Following release, the biological control agent is expected to establish permanently from relatively small founder populations, and that these populations will independently reproduce and spread and become self-sustaining (ISSG 2018). The introduction of invertebrate herbivores for classical biological control of weeds has a long history. Since 1836, 551 biological control agents targeting 224 weeds have been released in 130 countries around the globe (Winston et al. 2014).

To understand the biology of an invasive alien weed and the factors that regulate its populations, including mortality or damage caused by natural enemies, research must be conducted in the area of origin of the weed (Briese 2000; van Driesche and Hoddle 2000). Once a candidate agent has been discovered it must be authoritatively identified and assessed to determine if it is safe to introduce into the region that the weed has invaded. Studies are conducted to determine if the candidate biological control agent poses any risk to other, non-target species. This research is carried out both in the area of origin (provider country) and the area of introduction (recipient country), the latter under quarantine

D. Smith · D. Djeddour

CABI, Bakeham Lane, Englefield Green,

Egham TW20 9TY, UK

P. G. Mason $(\bowtie)$

Agriculture and Agri-Food Canada, Ottawa Research and

Development Centre, 960 Carling Avenue, Ottawa,

ON K1A 0C6, Canada

e-mail: peter.mason@canada.ca conditions (Briese 2000; Schaffner et al. 2018). Once an appropriate biological control agent has been approved, released and demonstrated effective control of the target weed, it may be considered for introduction into other countries where the weed has invaded.

Classical biological control of weeds (CBCW) has experienced many successes and $65.7 \%$ of the weeds targeted for biological control resulted in some level of control (Schwarzländer et al. 2018). Among these, some have been dramatic. In Africa, the release of Neochetina eichhorniae Warner and N. bruchi Warner (Coleoptera: Curculionidae) led to the significant decline of the invasive alien water hyacinth, Pontederia (=Eichhornia) crassipes Mart. (Commelinales: Pontederiaceae), thus contributing to the well-being of some 30 million people (Collis 2000). In Australia, introduction of the cactus moth Cactoblastis cactorum (Berg) (Lepidoptera: Pyralidae), and the mealybug Dactylopius opuntiae (Cockerell) (Hemiptera: Dactylopiidae), resulted in spectacular control of prickly pear cactus, Opuntia spp. (Caryophyllales: Cactaceae) (Julien 2006; Page and Lacey 2006).

Historically, CBCW has been conducted under the principle of free multilateral use and exchange of the agents (Cock et al. 2009, 2010). Under this principle any country could have access to a proven biological control agent whether the source country is the original provider of the agent or has an established population (having previously received the biological control agent from the original source country) that can be collected and shipped to another country not involved in the original project. After the initial investment, the only costs to succeeding recipients were those associated with collecting, shipping and release of the agent in that country. Currently, costs to meet the regulatory requirements of succeeding recipient countries must also be included.

The principle of free multilateral use and exchange of proven biological control agents has provided benefits globally. In the cases of developed countries it has enabled rapid implementation of biological control programs in response to new invasive alien species. For example, Australian researchers found that Chrysolina quadrigemina Suffrian and C. hyperici Förster (Coleoptera: Chrysomelidae), both originating from France, were effective biological control agents for St. John's wort, Hypericum perforatum (Malpighiales: Hypericaceae), in Australia-subsequently these species were released in California, USA 
and New Zealand where they significantly reduced populations of $H$. perforatum (Briese 1997). Free multilateral use and exchange of biological control agents has also allowed developing countries to benefit from research and implementation carried out by wealthier countries, particularly in subtropical and tropical regions, where work by Australia, South Africa, and the USA has been of direct benefit to developing countries in these regions (Cock et al. 2010). For example, the discovery and successful implementation of the salvinia weevil, Cyrtobagous salviniae Calder \& Sands (Coleoptera: Curculionidae), for biological control of salvinia floating fern, Salvinia molesta Mitchell (Salviniales: Salviniaceae), in Australia led to subsequent releases of the agent in India, Kenya, Malaysia, Namibia, Papua New Guinea, South Africa, Sri Lanka and Zambia (Cock et al. 2010 case study 11). In Argentina, invasive Tamarix spp. (Caryophyllales: Tamaricaceae) are targeted for classical biological control through the release of Diorhabda spp. (Coleoptera: Chrysomelidae) beetles, that were previously tested and released in the USA (Mc Kay et al. 2017). The search for biological control agents for strawberry guava or araçá, Psidium cattleianum Sabine (Myrtales: Myrtaeae), invasive in Hawaii, led to a long-term co-operative agreement between the US National Park Service and the University of Hawaii in the USA and the University of Paraná in Brazil and ultimately the establishment of a biological control research group at Curitiba, Paraná (Pedrosa-Macedo et al. 2000). In South Africa, CBCW has been successfully used since 1913 as a management tool for the control of mainly environmental weeds, such as the release of Dactylopius ceylonicus (Green) (Hemiptera: Dactylopiidae) to control the cactus Opuntia monacantha Haw. (Caryophyllales: Cactaceae) (Zachariades et al. 2017). Some 313 species of insects, mites and pathogens from various areas of the world have been considered and 119 of them proved suitable for release against invasive plant species (Zachariades 2018). Thus, the South African environment has benefited considerably from the biodiversity of other countries.

There are warning signs that $\mathrm{CBCW}$, a noncommercial public good activity, could be at risk if countries adopt regulatory requirements that are too restrictive and negatively affect the efficient and effective multilateral exchange and use of proven biological control agents (Smith et al. 2018). Within this framework, two international agreements regulating access to genetic resources and benefit-sharing (ABS), the Convention on Biological Diversity (CBD), which entered into force on 29 December 1993, and the Nagoya Protocol (NP), a supplementary instrument to the Convention, which became effective on 12 October 2014, are of concern.

The CBD and the NP empower ratifying countries (Parties) to regulate access to genetic resources under their national jurisdictions (CBD article 15.1 and NP article 6.1). If this occurs, and subject to relevant domestic legislation, access to a country's genetic resources is on condition that prior informed consent (PIC) is obtained (CBD article 15.5 and NP article 6.1) and mutually agreed terms (MAT) are elaborated (CBD article 15.4 and NP article 5.1). A permit or its equivalent must be issued by the providing country as evidence of the decision to grant PIC and the establishment of MAT (NP article 6.3.e). Access to genetic resources for non-commercial purposes, such as is the case of $\mathrm{CBCW}$ research and practice, is meant to be promoted and facilitated (NP article 8.a). To that end, Parties shall create special conditions and adopt simplified regulatory requirements in the development and implementation of their respective domestic legislation (CBD article 15.2 and NP article 8.a). The NP established that to ensure compliance with domestic access regulation, each Party shall take measures to ensure that genetic resources utilized within its jurisdiction have been accessed in accordance with PIC and that MAT have been established (NP articles 15 and 17).

Some countries have not undertaken a strategic planning process before adopting their national ABS legal frameworks or considered that regulating access to genetic resources under their jurisdictions is not an end in itself, but a pathway to achieve benefit-sharing and contribute to the conservation of biological diversity and the sustainable use of its components (Glowka 2000). As a consequence, non-commercial research on genetic resources, including $\mathrm{CBCW}$ research and practice-an approach recognized by the $\mathrm{CBD}$ as an effective tool to manage invasive alien species (Document CBD/COP/DEC/XIII/13)—has been hindered by non-strategic and poorly planned ABS national regimes (Cock et al. 2010; Neumann et al. 2018; Prathapan et al. 2018; Smith et al. 2018).

This paper illustrates some of the common problems that may be encountered by researchers and 
practitioners around the globe when trying to access biological control agents for $\mathrm{CBCW}$ projects. As examples, it reviews the national ABS legal frameworks of Argentina, Brazil and South Africa, and processes in the USA and Canada where ABS legislation resulting from the NP has not been implemented. The objective is to examine how access, exchange and utilization of weed biological control agents in these countries are affected by domestic ABS regulations that are in force. In the cases of Argentina, Brazil and South Africa, a provider's perspective is taken, highlighting the unique obstacles created by the legal ABS system for accessing and exporting biological control agents in each country. In contrast, in the cases of the USA and Canada, different user and recipient approaches are highlighted, focusing on how these countries cope with existing international and national legal regimes on ABS when they import and utilize biological control agents in their own jurisdictions. Finally, the paper draws on the experience of $\mathrm{CABI}$, an international not-for-profit organization, in applying best ABS practices for access, exchange and utilization of biological control agents.

\section{The cases of Argentina, Brazil, South Africa, the USA, Canada and CABI}

\section{Argentina}

Argentina became a Party to the CBD on February 20, 1995 and to the NP on March 9, 2017. According to its National Constitution, provinces have ownership over the natural resources found within their territories (National Constitution article 124). Therefore, the provinces are empowered to provide consent for access to genetic resources under their respective jurisdictions. The Federal Government is responsible for adopting, through the National Congress, minimum legal environmental standards that guarantee a common level of environmental protection across the country and the provinces are responsible for creating their own regulations to enforce the Federal rules (National Constitution article 41). If genetic resources occur within a National Park, then approval for collecting must be arranged with the individual Park.

The Federal Government has so far not adopted a law setting minimum legal environmental standards on ABS. Instead, certain aspects of an ABS regime have been regulated through Administrative Decision No. 226/2010, adopted by the Argentine Secretariat of Environment and Sustainable Development (SE\&SD). The Decision only applies for access to genetic resources when they are to be later exported (Administrative Decision No. 226/2010 article 1). Within this limited scope, evidence of the existence of the PIC granted by the respective province or National Park and of the MAT established must be presented to the SE\&SD when genetic resources are to be exported (Administrative Decision No. 226/2010 article 1 and Appendix 1). Subsequently, the SE\&SD issues an export permit.

In addition to Administrative Decision No. 226/2010, ten provinces out of the existing 23 (namely, Misiones, Neuquén, Santa Cruz, Tierra del Fuego, Catamarca, Jujuy, San Luis, Entre Ríos, Formosa and Buenos Aires) have regulated ABS issues to a different extent. The main differences amongst provincial regulations are the formal and substantial requisites required to grant access to genetic resources, the material scope of the legislation, the obligations and conditions imposed on users of genetic resources, and the kind of benefits arising from the utilization of genetic resources that are expected to be shared with the province.

The main challenge of the Argentine ABS legal framework is the lack of an ABS law setting minimum environmental standards throughout the country. As a consequence, the ten provinces in Argentina that have adopted ABS regulations have requirements that greatly differ from one another, while the other 13 provinces have not regulated the issue to any extent. The disparity is overwhelming and confusing for institutions from recipient countries trying to gain access to biological control agents. In addition, the ABS national and provincial legal systems are neither strategic nor efficient - they do not establish simplified requirements and procedures for non-commercial research of genetic resources. Consequently, collection of biological control agents in Argentina and their export are unnecessarily overcomplicated.

Thirdly, researchers may find themselves trapped in a legal loophole as the evidence required to issue an export permit by the SE\&SD — proof that PIC has been granted by the corresponding province-cannot always be obtained due to the fact that more than half of the provinces do not require any ABS documentation (i.e. PIC and MAT). To solve this complication, 
provinces provide de facto a letter or some other kind of written evidence stating they do not oppose the utilization and export of the resources. The note, which has a doubtful legal value, still serves as a basis for applying for the export permit as the SE\&SD is fully aware of this conundrum. Finally, on top of the difficulties described, other complications arise as the user of biological control agents may also need to satisfy a different set of legal obligations. These focus on phytosanitary and conservation concerns, the interprovincial transport of biological material, the collection of biological control agents, etc. The lack of coordination between all these regulations at the national and the provincial levels has created great inefficiencies and confusion amongst researchers and practitioners.

As a consequence of the issues noted above, since 2010 when Decision No. 226 was adopted, it has become increasingly difficult to access genetic resources in Argentina and to transfer them abroad for $\mathrm{CBCW}$ purposes. The following examples draw on some of the explained challenges.

In December 2017, the Argentine Foundation for the Study of Invasive Species requested authorization for the collection of the mining fly Thrypticus truncatus Bickel \& Hernández (Diptera: Dolichopodidae), a natural enemy of water hyacinth, P. crassipes, to the Directorate of Flora and Fauna of the Province of Buenos Aires. The authorization was granted in June 2019, one and a half years after the application was filed. This was just the beginning of the process as Fundación para el Estudio de Especies Invasivas (FuEDEI) now has to collect the mining flies, an activity that might take approximately one month. After that, transport guides, a mandatory document for the inter-provincial transport of biological material, will have to be obtained. In addition, PIC to access genetic resources of the mining fly will have to be requested from the competent authority of the Province of Buenos Aires. Once the PIC is secured, FuEDEI will require an export permit from the SE\&SD in order to export the flies to the Western Regional Research Center of the US Department of Agriculture in the USA. The entire procedure might take between two to three years from the moment the collection permit was requested and the final export permit granted. Authorities from different jurisdictions (provincial and national) will have to be approached and a variety of laws addressing authorizations for collection of biological material, the inter-provincial transport thereof, access and utilization of genetic resources, exportation of resources and phytosanitary aspects will all have to be satisfied.

Another example that demonstrates the challenges presented by the national and provincial ABS legislations is the following case. FuEDEI requested authorization from the Secretary of Environment of the Province of La Rioja in November 2017 to collect Coelocephalapion gandolfoi Kissinger (Coleoptera: Brentidae). The weevil is intended to be exported to the Agricultural Research Council in South Africa for testing, and eventually utilized as a biocontrol agent against invasive mesquite, Prosopis spp. (Fabales: Fabaceae). Supporting documentation for collection of biological material in this case included a description of the research project and an institutional endorsement letter from FuEDEI.

After an authorization for collection of insects was granted in June 2018, PIC to access genetic resources contained within them was requested by the same Secretary. An important problem then arose as the Province of La Rioja has not regulated ABS and, therefore, it cannot lawfully consent to the access and utilization of genetic resources found within its jurisdiction. To solve this issue, FuEDEI ended up obtaining in March 2019 an authorization stating that the province did not oppose the export and use of $C$. gandolfoi as a biological control agent. The provincial authorization does not constitute, strictly speaking, a PIC that consents access to genetic resources.

Export permitting process will be initiated by FuEDEI in September 2019. The provincial authorization FuEDEI has obtained from the Province of $\mathrm{La}$ Rioja is likely to be considered sufficient evidence of the existence of the PIC by the SE\&SD and, consequently, the export permit is likely to be issued. The entire process from the request for a collection permit to the granting of the export permit will take around two years.

In contrast to the two previous examples, in 2018 FuEDEI obtained a PIC from the Directorate of Flora and Fauna of the Province of Buenos Aires and an export permit for SE\&SD for the use of the water primrose thrips, Liothrips ludwigi Zamar, Hernandez, Soto-Rodriguez \& Retana-Salazar (Thysanoptera: Phlaeothripidae), in only three months (Silvestri et al. 2019). Insects were then exported to the Western 
Regional Research Center of the US Department of Agriculture in the USA to determine the potential of $L$. ludwigi to control invasive water primrose, Ludwigia spp. (Myrtales: Onagraceae). Although the reasons for the rapid approval of the permit are unclear, successful cases like this one will hopefully become more common in the future.

Recognizing the above-mentioned challenges, the SE\&SD has undertaken a national project under the auspice of the Global Environmental Facility and the United Nations Development Program with the aim to contribute to the effective national implementation of the NP in Argentina. Within its framework, the SE\&SD has prepared a legislative draft proposal that establishes minimum legal environmental standards on ABS across all provinces. The proposal, however, has been contested by the local scientific community claiming it does not provide simplified measures for non-commercial access and utilization of genetic resources.

\section{Brazil}

Brazil is a Party to the CBD and a signatory of the NP since May 1994 and February 2011, respectively. Although Brazil is an important provider of genetic resources worldwide and played a critical role at the international negotiations that led to the adoption of the NP, the National Congress has not yet ratified it. However, lack of ratification has not prevented Brazil from updating its ABS national system to include the provisions of the NP.

The cornerstones of the current legal framework are Law No. 13123 of 2015 that regulates the access to Brazilian genetic heritage and associated traditional knowledge, and the sharing of benefits arising from their utilization, and Decree No. 8772 of 2016 that implements the new law. The previous Provisional Administrative Measure (Medida Provisória) No. 2186-16 of 2001 has been repealed. Contrary to the previous regulatory framework, the new system attempts to strike a balance between meaningful benefit-sharing and the need to provide legal certainty to users of resources at a low transaction cost.

Central to the scope of the Brazilian ABS system is the notion of "genetic heritage" (Law No. 13123 article 2.1). It is a far-reaching concept that not only includes the structure of genetic resources and their derivatives, but also the key notion of genetic information, that is to say the intangible, and frequently most valued aspect of plant, animal and microbial genetic resources. Consistent with this approach, Brazilian legislation covers the utilization of digital genetic information that could be associated with its genetic heritage when this information has been published in any national and/or international databases and its utilization enables a research project or a technological development (Decree No. 8772 article $107 \mathrm{VI}$ ). Whether the use of digital sequence information does or does not fall within the ABS international regime is under discussion and pending on a decision of the Parties of the CBD.

The new legislation established the National System for Genetic Heritage and Associated Traditional Knowledge Management [Sistema Nacional de Gestão do Patrimônio Genético e do Conhecimento Tradicional Associado (SisGen)], an online self-registration and notification system that requires access to any Brazilian genetic heritage and to associated traditional knowledge to be informed, managed and monitored (Decree No. 8772 chapter IV). The system is operated by the Genetic Heritage Governing Council [Conselho de Gestão do Patrimônio Genético (CGEN)].

PIC is no longer required to access Brazilian genetic resources. Instead, any access to Brazilian genetic heritage that is taking place inside or outside the country must be electronically reported in SisGen (Law No. 13123 article 12). In addition, the export of any material containing Brazilian genetic heritage with the intention to access it abroad or to provide any service based on it, has to be registered in SisGen (Law No. 13123 article 12). Furthermore, shipments for research purposes must be linked to a Material Transfer Agreement (MTA) with a Brazilian research institution (Law No. 13123 article 11.2). Registration in SisGen must be done before any scientific results are published or prior to the export of the genetic material occurs (Law No. 13123 article 12.2). These ABS regulatory requirements are applicable to research on and the export of Brazilian biological control agents for CBCW.

The existing ABS legal scheme does not regulate the collection of biological material, the trapping of animals, the transport thereof, or the involvement of foreign researchers in collecting activities. These actions, however, are regulated under other laws that require registration in different systems and 
independent authorizations. Research on biological control agents and the export thereof for $\mathrm{CBCW}$ purposes are likely to be covered by these regulatory requirements as well. For example, a registration is needed in the System for Authorization and Information about Biodiversity [Sistema de Autorização e Informação em Biodiversidade (SISBio) from the Institute Chico Mendes of Biodiversity Conservation (ICMBio)] in case ABS activities involve the collection of any biological material or take place inside federal protected areas or in caverns. Likewise, if foreign researchers are involved in the collection of biological resources or their research, an authorization has to be requested from the National Council for Scientific and Technological Development [Conselho Nacional de Desenvolvimento Científico e Tecnológico $(\mathrm{CNP} q)$ ]. Similarly, biological samples to be exported require an export authorization from the Brazilian Institute of Environment and Renewable Natural Resources [Instituto Brasileiro do Meio Ambiente e dos Recursos Naturais Renováveis (IBAMA)] under the Convention on International Trade in Endangered Species of Wild Fauna and Flora (CITES)/Non CITES system [Sistema de emissão de Licenças Cites e não Cites (Siscites)].

The new ABS system is likely to have both beneficial and unfavourable consequences for $\mathrm{CBCW}$ related activities. On the one hand, there is no longer a need to obtain prior authorization or a permit to access genetic resources. Only a registration in SisGen is now required. This means the procedure to be followed when the user of biological control agents intends to pursue research or to export them abroad is simplified. Another advantage of the current ABS scheme is that it has been designed in a way that allows the continuation of ongoing $\mathrm{CBCW}$ research projects providing that the user of the Brazilian genetic heritage currently registers the relevant activities in SisGen.

On the negative side, the new ABS system has unintentionally created redundancies and added additional layers of bureaucracy that hinder efficient research on biodiversity (Alves et al. 2018). Practitioners working in the field of $\mathrm{CBCW}$ must register research on biological control agents and the export thereof in SisGen. In addition, registration in SISBio and authorizations issued by $\mathrm{CNPq}$ and IBAMA are likely to be required. Mandatory registrations and authorizations entail more time spent and greater workload. Furthermore, translation of some documents into English and expert legal counseling will probably be needed. Estimated processing time for registrations and authorizations will probably require at least eight to ten months, potentially negatively impacting the research and efficient exchange of biological control agents.

An example that illustrates the challenges noted above was the case of a $\mathrm{CBCW}$ research project that entailed the export of two biological control agents: the pit gall maker Calophya terebinthifolii Burckhardt \& Basset (Hemiptera: Calophyidae) and the sawfly Heteroperreyia hubrichi Malaise (Hymenoptera: Pergidae) from the Blumenau University in Brazil to the USA for control of the Brazilian Peppertree Schinus terebinthifolia Raddi (Sapindales: Anacardiaceae). It required one month to gather all the necessary information (personal and institutional data, description of the project activities, etc.) to proceed to registration in SisGen. After this, the relevant documents were sent to the University of Florida, USA for translation and signature. This took two more months. Once back in Brazil, applications were sent to different governmental agencies- $\mathrm{CNPq}$ and IBAMA - for approving the involvement of a foreign researcher in the scientific expedition and the export of the biological control agents, respectively. Each of these procedures took two more months. Once all authorizations were obtained, it took another month to update and finish entering the required information in SisGen in order to export the samples to the USA. Overall, eight months were required to obtain approval to collect and export the two CBCW agents.

Another example is the case of a $\mathrm{CBCW}$ collaborative project between the Commonwealth Scientific and Industrial Research Organization (CSIRO) in Australia and the Blumenau University in Brazil. In this case, the biological control agents Paracoccus spp. (Hemiptera: Pseudococcidae) and Trupanea bonariensis (Brethes) (Diptera: Tephritidae) were to be exported to Australia with the intention to test them for control of Flaxleaf fleabane Conyza bonariensis (L.) Cronquist (Asterales: Asteraceae). The process to authorize export took only four months, but the time needed to obtain approval for the scientific expedition has not been considered and this could take four more months. In this case, only two weeks were required to obtain the needed signatures from Australian authorities and return the documents to Brazil. In addition, the time to obtain the export permit decreased from 
two months to one month compared to the previous example. The most likely reason behind the partial enhancement of the process could be the changes introduced to SisGen after its first months of operation. The system now provides a MTA template that must be used by Brazilian and foreign research institutions when biological control agents will be shipped abroad, and a check list of all necessary requirements to be met in order to request an authorization for scientific expeditions. All documents are now also available in English, an improvement that probably has helped reduce paper work and the need for translation.

\section{South Africa}

South Africa has been a Party to the CBD and the NP since 1996 and 2014, respectively. The country had a well-developed ABS legal framework in place before the NP was adopted. This was as a response to decades of unlimited and unconsented access to South African natural resources upon which high-value-added products were developed without any benefits for the country (Crouch et al. 2008).

The first ABS national legal provisions were adopted in 2004 within the framework of the National Environmental Management Biodiversity Act (Act No. 10 of 2004) (NEMBA or Biodiversity Act). In 2008, the Bioprospecting, Access and Benefit Sharing (BABS) Regulations were adopted and further developed the system. In 2015, BABS Regulations were amended. The national Department of Environmental Affairs (DEA) (now the Department of Environment, Forestry and Fisheries-DEFF) administers NEMBA and BABS and also hosts the national focal point and the national competent authority for the implementation of the CBD and the NP.

The South African legal scheme has a wide material scope. This has unique consequences and differs greatly from the extent of application of the international ABS regime which only covers genetic resources and their derivatives (CBD article 2 and $\mathrm{NP}$ articles 3 and 2.c, $\mathrm{d}$ and e). Regulations are applicable to all indigenous biological resources (IBR) and indigenous genetic resources (IGR) (BABS Amendment Regulations section 3). That includes all indigenous species, all of their genes, biochemical compounds and information as long as they pertain to a species that occurs, or has historically occurred, naturally in a free state in nature within South Africa
(NEMBA sections 1 and 80.2 and Amendment of Act No.10 of 2004 section 1 by Act No.14 of 2013 section 1.I.).

The range of activities encompassed under the regime is also vast. It applies to bioprospecting, which not only includes the research on, development or application of IBR and IGR for commercial or industrial exploitation, but also the cultivation and propagation of IBR, amongst other activities, as long as they are used as an input to the production of more processed products such as medicines, industrial enzymes, essential oils, food flavourants, etc. (Department of Environmental Affairs 2012).

The regime therefore applies to a multiplicity of situations that do not actually constitute a genuine access and/or utilization of genetic resources. The ABS legal framework also covers the export of any IBR and IGR for research purposes undertaken by non-commercial sectors and bio-trade, that is to say the buying and selling of milled, powdered, dried, sliced or extract of IBR and IGR for further commercial exploitation (BABS Amendment Regulations sections 3.1.a and c).

Key provisions of the Act demand that anyone engaging in bioprospecting involving IBR and IGR is obliged to obtain a permit (NEMBA section 81.1.a). In addition, a user of IBR and IGR interested in exporting them for bioprospecting purposes or any other kind of research must obtain a permit as well (NEMBA section 81.1.b). Before any permit is issued, the interests of the person providing or giving access to the IBR and IGR and those corresponding to any indigenous communities whose traditional uses or knowledge of the utilization of the IBR contribute in any manner to the proposed project, have to be protected (NEMBA section 82.1.a and b). If this is the case, the permit may only be issued if PIC has been obtained and the applicant and relevant stakeholders have entered into a MTA (export of IBR and IGR) and a benefit-sharing agreement (bioprospecting project) (NEMBA sections 82.1.a and 82.2.b).

Some activities undertaken in the field of CBCW may fall within the scope of the current scheme on ABS. A first situation to distinguish this occurs when a user of IGR or IBR undertakes surveys for potential biological control agents within South Africa. CBCW research is by definition intended for non-commercial purposes. As such, activities undertaken within the scientific project do not constitute bioprospecting and 
are not covered by the ABS legislation, so there is no need to either notify authorities or obtain any kind of permit under the Act and the Amended BABS. The user may only need to obtain a collection and/or research permit from the competent provincial authority, provided that provincial legislation requires this for such activities. In addition, the researcher must obtain authorization from the land owner where the resources are located in order to access them.

A different situation occurs when a user of IGR and IBR collects, gathers, or by any other means accesses these resources from in situ conditions in order to later export them for $\mathrm{CBCW}$ purposes; that is to say, has non-commercial research intentions. In this case, the ABS legislation is applicable and the interested party will have to apply for an export permit for research other than bioprospecting (NEMBA section 81.1.b and BABS Amendment Regulations section 19.1). On the application form the user will have to specify the kind, quantity and source of IGR and IBR involved and the purpose for which they will be exported (NEMBA section 81.1.b and BABS Amendment Regulations sections 19.1 and 19.3).

The issuing authority, the relevant provincial departments under which environmental affairs fall (in the name of each provincial MEC $=$ Member of the Executive Council, i.e. the provincial minister responsible for environmental affairs), will have to consider, before issuing the permit, the potential impacts of removal of populations of potential natural enemies on the integrity of the ecosystem and how these impacts will be minimized or remedied (BABS Amendment Regulations section 27). In this situation the researcher will again need to obtain an authorization from the owner of the resources or of the land where resources are located in order to access them.

A third situation occurs when resources to be exported come from an ex situ collection, for example, from a herbarium, germplasm bank, etc. In this case, there is no obligation to obtain an export permit for research other than bioprospecting, providing that an exchange agreement is concluded between the exporter (the local scientific institution) and the importer (a foreign scientific institution), and the provincial competent authority is notified (Biodiversity Act 10 of 2004: Notice of Exemption in terms of section 86. Government Notice R149).

Some of the main challenges the South African legislation presents are increasing bureaucracy and the significant workload it demands to get all permits needed for IGR and IBR for CBCW research. First, a collection/research permit is needed as explained. Then, an export permit for research other than bioprospecting has to be obtained. Before applying for those permits, the authorization of the owner of the resources or the land has to be sought. In addition, although the legislation is in place, it has been poorly publicized and thus landowners are unaware that their written permission is required for collection, researchers are not aware of the process and thus often fail to comply, but importantly the regulatory authorities themselves are not well versed in the legislation. Recently, for example, the herbivorous ladybird beetle Cleta eckloni Mulsant (Coleoptera: Coccinellidae) was exported by the Centre for Biological Control, Rhodes University, South Africa, to CSIRO, Australia for testing as a potential biological control agent against the South African plant Lycium ferocissimum Miers (Solanales: Solanaceae) which has become invasive there. The researchers were required to spend considerable time educating landowners who were happy to allow the collection to take place on their properties, but reluctant to give written permission as they felt that they may be held liable if anything went wrong. The provincial authorities were also not sure which directorate was responsible for signing off on permission and needed explanation from the researchers as to the biological control procedures. Many of the provincial authorities were oblivious to the science of $\mathrm{CBCW}$. So, although the legislation is in place, there is a definite need for training.

If time frames for the issuing of the export permit alone are considered, the process might take up to 120 working days (BABS Amendment Regulations section 21.1). If additional information is required from the applicant by the authority, the process might take longer. Finally, another weakness the legal framework shows is that provisions are scattered amongst the 2004 Act, its Amendments of 2004, 2009 and 2013, and the old and new BABS. This is likely to disconcert applicants as it is hard to understand how the system works and to initiate the application process fully aware of its operation.

Some of the strengths the system features are the need for a foreign research institution that wishes to obtain a permit under the Act and BABS to jointly apply for it with a South African research institution or a South African researcher (BABS Amendment 
Regulations section 12). This is likely to promote scientific collaboration between foreign and local research institutions. In addition, the existence of differentiated and facilitated processes and requirements for pursuing non-commercial research on IBR and IGR is a strength that can be mentioned. Both of these are critical for researchers working in the field of CBCW.

Since NEMBA was adopted before the NP entered into force, legislation is currently going through amendment. Even though specific changes are not known yet, it is expected DEA will conduct consultations with the main stakeholders involved in ABS practice, including the $\mathrm{CBCW}$ community. Representatives of the $\mathrm{CBCW}$ community have been in discussion with DEA for the past 18 months on the interaction between the NP and the discipline of $\mathrm{CBCW}$ in South Africa, and continue to engage on a regular basis with DEA.

Lastly, the fact that South Africa has a long history in controlling invasive alien plants through $\mathrm{CBCW}$, and is considered among the top five countries in doing so (Schwarzländer et al. 2018), may have had a positive influence on legislation allowing it to also function as a provider country. This is because CBCW has delivered substantial benefits to South Africa and is generally viewed positively in the country. This has helped the dialogue between the government department that regulates biological control (Department of Agriculture) and DEA. The magnitude of the negative impact of invasive alien plants on the economy, biodiversity and agricultural output of South Africa may also have resulted in increased empathy for other countries suffering similar problems. As a result, the export of organisms for $\mathrm{CBCW}$ of South African plants invasive in other countries has remained relatively easy despite the above-mentioned legislation related challenges.

\section{USA}

The United States of America (USA) is one of the 17 countries identified as the most biodiversity-rich countries of the world, with a focus on endemic biodiversity (UNWCMC 2019), but the USA is not Party to the CBD or the NP and presents a unique situation compared to all other countries. With its wide range of habitats, from arctic to semi-tropical, the USA has served as a source of introductions of plants around the world since European colonization. In general, the USA does not restrict surveys, collections, or study of native USA organisms with the purpose of identifying potential biological control agents that could be exported to other countries to control introduced North American weeds. Because of the diversity of environments, the USA is also vulnerable to invasion by alien species from around the globe. Although the USA has not ratified either agreement, protection of biodiversity in other countries that have signed the CBD and/or the NP is having a direct impact on the way USA institutions conduct foreign explorations for biological control agents.

As a provider of biological control organisms, the USA has supported the principle of free use and exchange. In fact, the USA, through foreign aid programs (e.g. USAID), has assisted developing countries to develop their own biological control programs. On most private lands in the USA, there are no permitting requirements to conduct $\mathrm{CBCW}$ and to collect agents of interest for taxonomical or biological studies, or even transport biodiversity out of the country. Permission to collect biodiversity is granted by the private landowner. Exceptions do apply to biodiversity listed as rare and/or endangered species and collections/studies made on lands owned and or managed by Tribal, Federal, or State entities. The US Fish and Wildlife Service (USFWS) maintains web sites that contain information on and lists of threatened and endangered species (USFWS 2019). Practitioners of $\mathrm{CBCW}$ are encouraged to contact Regional and Local Field Offices of the USFWS in the areas where they plan to conduct surveys and/or collections in advance to obtain advice and guidance regarding any threatened, endangered, proposed, or candidate species. Whether or not collections of biological control agents include endangered species, surveys and collections of biodiversity on lands such as Indian Reservations and National or State Parks, Forests, and Scenic Rivers require approval and permits from the agency responsible for managing the land. Each Tribal, Federal, State, and Local Government landholder has their own permission and permitting process to allow studies and collections on their property. If arthropods or non-commercial pathogens are moved across state lines before they are exported or for additional studies, a "Permit to Move Live Plant Pests, Noxious Weeds, and Soil" (P526) is required 
from the Animal and Plant Health Inspection Service (APHIS and USDA 2019).

As a user of biological control resources from other countries, the USA established its own biological control laboratories around the globe, including in Argentina (previously the USDA-sponsored South American Biological Control Laboratory, now FuEDEI), Australia (Australian Biological Control Laboratory-ABCL), China (Sino-American Biological Control Laboratory-Sino-ABCL), and Europe (European Biological Control Laboratory-EBCL). These laboratories provide a base from which CBCW studies take place, including exploration for and shipment of biological control agents. The USA also develops collaborations with neighboring countries, in particular Canada, for weed biological control projects through consortia whereby resources are pooled. To access biological control agents, the USA signs agreements with countries hosting their biological control laboratories, but also with Universities, Federal, State, and Local scientific organizations in countries with or without USDA-affiliated biological control laboratories.

With the adoption of ABS legislation by countries where the USA has current or planned $\mathrm{CBCW}$ projects, obtaining permits to export potential biological control agents, and even surveying or studying the biodiversity, has become increasingly difficult, time consuming, and erratic. These impediments are not unique to the USA but also affect other countries conducting $\mathrm{CBCW}$, including South Africa, Canada, and Australia. In some cases, projects have been abandoned due to difficulties and delays in satisfying requirements of various country's interpretations of protecting biodiversity. Continued work in $\mathrm{CBCW}$ by the USA in countries such as Brazil and Argentina is threatened by the lack of consistent, timely, and science-based biodiversity protection protocols and guidelines. To evaluate the impact of the CBD and NP on $\mathrm{CBCW}$ workers in the USA, a non-rigorous questionnaire was prepared and presented to a group of scientists attending the 2019 annual meeting of the Technical Advisory Group (TAG), an independent, multi-agency, advisory committee to APHIS on the safety and worthiness of CBCW projects. A fourquestion questionnaire was handed out to 20 scientists attending the meeting (Supplementary Table S1). Three responders were not included because one was a European scientist and two conducted biological control with native agents. Of the 17 included responders, 11 worked for Federal Agencies and six worked for State Agencies (Universities or Agriculture Departments). Data from this small sample of respondents was limited and conclusions of responses should be considered only as indicative of broader trends. As a group, scientists of $\mathrm{CBCW}$ responded that their knowledge level of ABS was moderate (in the middle of a five-point scale), and basically half (56\%) expressed serious concern that the new ABS rules were negatively impacting their work in other countries (Supplementary Table S1). Scientists identified 14 countries where they either had current $\mathrm{CBCW}$ projects or did not have projects due to concerns about ABS (Supplementary Table S2). Countries where scientists had interest in a CBCW project but were not proceeding because of ABS concerns included Argentina, Brazil, India, Iran and Turkey. Other scientists had knowledge about ABS but were not concerned about conducting $\mathrm{CBCW}$ projects in Argentina, Brazil, and India. Argentina and Turkey were the countries most cited as places to not conduct CBCW due to ABS concerns; South Africa, Australia, and China were identified as countries where ABS concerns did not block work on $\mathrm{CBCW}$; and Brazil was a concern for some scientists but still a country to conduct CBCW by a majority of scientists. In 2009, Cock et al. (2010) expressed concern that most CBCW workers in North America were "not well-informed about the ABS issue". A slight increase in awareness of ABS impacts on $\mathrm{CBCW}$ projects may have occurred in our small sample of scientists, likely due to personnel interactions with countries implementing ABS rules. Requirements for permits to collect, export, and study biodiversity remain daunting in several countries, often requiring interactions with various government agencies that often have different requirements.

Canada

Although a Party to the CBD since 1993, Canada is not a Party to the NP. However, similar to other nonParties to the Protocol, Canada must comply with ABS legislation and processes implemented by providers of biological control agents. Furthermore, as a Party to the CBD, Canada must abide by its objectives, including the third objective, the fair and equitable sharing of the benefits of biodiversity. 
Environment and Climate Change Canada is the national focal point and future designation of competent national authorities will likely be sector-based, for example the agriculture, fisheries and forest sectors. Furthermore, as set out in the CBD, Canada is entitled to determine how its biodiversity will be accessed and the benefits from its utilization shared (CBD article 15.1). Canada has not developed an ABS policy nor has it defined how such measures would be implemented. However, it is certain that implementation of ABS measures, domestic or foreign, will impact biological control programs in Canada (Mason et al. 2018).

As a provider of biological control agents, Canada is guided by existing international agreements (e.g. CITES 1973), domestic legal mechanisms, such as common and civil laws of provinces governing ownership of property [e.g. Bill 190, Paragraph 9.2 (2), Respect for Private Property, Government of Ontario 2009], and best practices when collecting or transferring biological control agents (Mason et al. 2017). Permission from the appropriate authority (e.g. land owner, indigenous community, permits from federal, provincial municipal government, etc.) must be obtained in order to collect the organism.

Best practices have been developed to guide biological control scientists for provision of biological control agents that are naturally occurring in Canada (Mason and Brodeur 2013) and include documentation templates to confirm due diligence that the genetic resources were obtained legally (i.e. proper permissions were obtained and compliance with the Committee on the Status of Endangered Wildlife in Canada (COSEWIC) requirements) and are being supplied to the recipient without conditions (i.e. free use). Typically, there are no benefits to Canadians for providing biological control agents other than facilitating the management of invasive alien species in other countries (i.e. being a good global citizen).

As a user, Canada seeks biological control agents from the areas of origin of invasive alien weeds. Generally, these are from temperate climates in the northern hemisphere such as countries in northern Europe (United Kingdom, France, Switzerland, Germany, Serbia, etc.) and northern Asia (Japan, China, Mongolia). The user communities are primarily federal or provincial government agencies that are publicly funded. Access to biological control agents has traditionally been achieved through the principle of free use and exchange. CABI has been Canada's main provider of biological control agents with most originating from countries in Europe. As practiced globally, agents proving to be successful in Canada (i.e. a population that has established and demonstrates impact on the target) have then been shared with government agencies in other countries experiencing the same weed problem, for example Calophasia lunula Foudras (Lepidoptera: Noctuidae) for control of toadflax, Linaria spp. (Lamiales: Plantaginaceae) in the USA, and Trichosirocalus horridus (Panzer) (Coleoptera: Curculionidae) for control of nodding thistle, Carduus nutans L. ssp. nutans (Asterales: Asteraceae) in New Zealand. These international partnerships have also allowed Canada to access 'proven' biological control agents from those sources based on a simple request, for example, Spurgia esulae Gagné (Diptera: Cecidomyiidae) originally from Italy was provided by the USA for control of cypress spurge, Euphorbia cyparissias L. (Malpighiales: Euphorbiaceae) (Winston et al. 2014).

With the implementation of ABS legislation Canada's access to biological control agents has already changed. In addition to compliance with existing international law, such as CITES, Canada as a member country of CABI must now sign a formal MTA in order to obtain biological control agents supplied by CABI who have implemented this as part of their new policy on ABS (see below). The main challenge for Canada is that, on occasions where the MTA does not allow such use, Canada must also negotiate MAT directly with the provider country when use other than research comes into play.

\section{CABI}

CABI is a not-for-profit international organization with the mission of improving people's lives worldwide by solving problems in agriculture and the environment. It was established by a United Nations treaty-level agreement between 49 member countries (https://www.cabi.org/Uploads/CABI/about-us/ Documents/CABI\%20Agreement\%202016.pdf).

Each member country has an equal role in the organization's governance, policies and strategic direction, in addition to enjoying a number of privileges and services relating to its scientific expertise, products and resources. These include disease identification, capacity building and information products. CABI's 
operations must meet the $\mathrm{ABS}$ requirements of these member countries as well as the providers of biological control agents. In its work, CABI is in a unique position in that it is both a provider and a user of biological control agents and often acts as an intermediary between provider and user countries.

CABI has developed an ABS policy (https://www. cabi.org/about-cabi/business-policies/) and ABS best practice (Smith et al. 2018) built around the basic principles of the NP. CABI's ABS best practices aim to facilitate compliance with the different ABS legislation implemented in the countries in which it works and in those that provide genetic resources for CABI use. Since most of CABI's work is done through its global centers, $\mathrm{CABI}$ is aligning its $\mathrm{ABS}$ best practice to comply with these host country requirements. In Switzerland for example, CABI is in discussion with the Swiss Competent National Authority to get CABI's ABS best practice officially recognized in a public register established under the new legislation (Swiss Ordinance on Access to Genetic Resources and the Fair and Equitable Sharing of Benefits Arising from their Utilization (Nagoya Ordinance, NagO) article 6). The benefit of having a best practice recognized is that it is an accepted procedure that reduces the risk of non-compliance by the user and justifies a reduction in compliance checks. CABI has chosen to develop its best practice not only for compliance in the countries it operates its centers but also to use them as a basis for negotiating agreements in provider countries. For this purpose, a Memorandum of Understanding (MoU) on compliance with national access and benefit sharing requirements for the utilization of genetic resources has been signed between CABI and the National Authorities in Ghana and a second MoU is under negotiation in Pakistan. Additionally, CABI's best practices are being used in China, Chile, Kenya and Malaysia as a basis for negotiation.

Where clear ABS access processes are in place or where countries have decided not to regulate access to their genetic resources, the application for access and use are straightforward. However, difficulties arise where countries are still in the process of deciding the best approach and developing regulations, processes and legislation. Where legislation exists, the requirements can be difficult or impossible to fulfill and the processes are convoluted or complicated. This coupled with the fact that there is rapid turnover of responsible staff dealing with utilization and export of biological control agents (i.e. national focal points and competent national authorities) in many Party countries obtaining correct information on procedures for PIC and negotiating MAT is difficult. In addition, some difficulties are politically motivated and are thus hard to be overcome. This has resulted in many of the CABI $\mathrm{CBCW}$ projects to be delayed since timelines to obtain permission to access biological control agents can be very long (several months to years). Sometimes countries, for example Turkey, have been completely abandoned as suitable for CBCW research.

An example where CABI has faced difficulties related to the implementation of ABS national policies and has worked to ensure the compliant access to genetic resources is in India (for details see Hinz et al. 2019). CABI's Indian Station was established in 1957 , and marked the beginning of organized and systematic biological control research in India. In recent years, however, biological control projects and the associated exchange of biological control agents came under critical review with the appointment of several new senior managerial staff. The resulting bureaucratic and administrative processes which required clearance for the collection and export of biological control agents, from the relevant Government Ministries and the Department of Agricultural Research and Education (DARE), resulted in a three-year hiatus for CABI to export of biological control agents from India to the UK center.

In 2017, CABI developed and signed a comprehensive MoU with the Indian Council of Agricultural Research, concerning scientific and technical cooperation. A year later, a three-year collaborative work plan (2018-2020) was approved by the Department of Agricultural Research and Education. This involved detailed work plans for activities and biological control agents to be exported for each project. Although the processes are now in place to allow these projects to resume, they are subject to necessary protocols of export facilitation, which can be protracted for any new species requested. Furthermore, third party use of any exported biological control agents requires additional, and as yet untested, administrative process through the National Biodiversity Authority. Although a significant step forward, researchers at $\mathrm{CABI}$ are questioning the sustainability and applicability of the process involved and time spent for biological control initiatives with limited funding. 
Another example where $\mathrm{CABI}$ is in the process of developing suitable alternatives to ensure compliance with ABS national legislation and the progress of projects is in China. The Ministry of Ecology and Environment (MEE) has been tasked to lead the development of ABS legislation, estimated to be ready for enactment in 2021. CABI has ongoing projects in China and the export of biological control agents is imperative. For this interim period, it was recommended by the MEE to CABI to establish a collaborative research contract with its main national partner (the Institute of Plant Protection under the Chinese Academy of Agricultural Sciences), which should allow for the export of biological control agents (F. Zhang, Pers. Comm.). Again, CABI researchers are questioning the applicability of the process involved and time spent for biological control initiatives with limited funding. CABI has yet to implement this process but is working closely with MEE to establish compliant processes for the use of China's genetic resources.

In addition, CABI has adapted its operations at its UK center, to meet European Union (EU) ABS legal requirements for supply of microorganisms from its collection. CABI hosts almost 30000 strains from 142 countries as well as the UK National Collection of Fungus Cultures. CABI scientists collect and hold reference strains including many biological control agents of microorganisms, plants and insects. Legal clarity on use of the supplied microorganisms is provided through an MTA that includes the MAT of the provider country. To keep this current and compliant CABI living collection works closely with the European Culture Collections' Organization which is updating its core MTA and material deposit agreement texts (https://www.eccosite.org/ecco-core$\mathrm{mta} /$ ). European regulation offers the opportunity for suppliers of organisms to become 'registered collections' in order to allow recipients to exercise due diligence in sourcing their organisms by selecting 'registered collections' holdings. Such collections must demonstrate the capacity to consistently supply genetic resources to third parties for their utilization with the correct documentation [Commission Implementing Regulation (EU) 2015/1866 of 13 October 2015 laying down detailed rules for the implementation of Regulation (EU) No 511/2014 of the European Parliament and of the Council as regards the register of collections, monitoring user compliance and best practices]. Although the CABI collection is not considering becoming a 'European Union registered collection' for the moment, it relies on the criteria set for this purpose by the EU ABS regulation to ensure compliance and the exercise of due diligence.

$\mathrm{CABI}$ is still in the learning phase and has to cope with the fact that countries are still struggling to put in place practical and adequate processes to meet the requirements of the NP. Ultimately, CABI as an international organization is committed to the CBD and NP and its staff will ensure the compliant access and utilization of biological control agents in the countries where CABI works.

\section{Conclusions}

The review of the cases of Argentina, Brazil and South Africa, three major source countries of biological control agents, indicated that their respective national $\mathrm{ABS}$ regulations, adopted pursuant to the $\mathrm{CBD}$ and the $\mathrm{NP}$, have negative effects on $\mathrm{CBCW}$ research and practice. Furthermore, the experiences of the USA, Canada and CABI as users of biological control agents accessed from other countries, including Argentina, Brazil and South Africa, highlight that ABS legal requirements of source countries that are in force have had adverse impacts on CBCW programs.

The principle of free multilateral use and exchange of proven biological control agents has been an important component of CBCW and provided benefits to both developed and developing countries, allowing prompt implementation of biological control programs in response to new invasive alien species. This global benefit-sharing has, however, changed as providing countries of genetic resources rushed to adopt national ABS regulatory measures without undertaking a strategic planning process. As a consequence, ABS regimes can hinder the efficient access, utilization and exportation of biological control agents.

The international community recognizes that different international laws can create confusion for accessing agents for CBCW. Amongst them, the most important ones are the lack of simplified legal requirements and procedures for the access to genetic resources to pursue non-commercial research, such as CBCW programs. In addition, the implementation of redundant and bureaucratic procedures intended to 
control, in an uncoordinated manner, every single aspect of biodiversity research and/or biodiversity utilization, are a reason for worry. Moreover, the existence of legal loopholes and, contrary to that, the enactment of overlapping laws, creates confusion amongst $\mathrm{CBCW}$ researchers and practitioners. Scattered ABS regulations and disconnected multilevel decision-making processes also add to the problem. Finally, the lack of institutional capacities in most countries to handle ABS-related matters aggravates the situation.

This review does not question the noble objectives of the CBD and the NP which aim for a fairer and more equitable sharing of benefits arising from the utilization of genetic resources, and to the conservation of biological diversity and the sustainable use of its components. Neither does the review call into question the legitimate right of countries to benefit from their own natural biodiversity and to adopt legally binding measures to regulate their access and utilization. However, it emphasizes the unintended consequences ABS national regimes do have for $\mathrm{CBCW}$ research and practice.

Under this premise, we conclude that national policy makers need to understand the importance of biological control as a biodiversity service for agriculture and the environment. We encourage government authorities to adopt appropriate ABS-related national measures towards promoting the effective and efficient exchange of biological control agents. These could entail special legal or administrative considerations, including the implementation of simplified measures for the access and exchange of biological control agents for CBCW purposes or the plain exemption of these activities from the scope of the $\mathrm{ABS}$ regime.

As Argentina and South Africa prepare to adopt new ABS legislation they should seize the opportunity to properly address $\mathrm{CBCW}$ concerns in their respective future regimes. On the other hand, in Brazil, where latest changes to SisGen seem to be a cause for optimism, efforts should be made to streamline different registrations and authorizations required under different laws under one single system.

Acknowledgements Ms Lactitia Tshitwamulomoni (National Focal Point - South Africa) is thanked for consultation on ABS and the NP. Philip Weyl, David Smith and Djami Djeddour were supported by CABI, with core financial support from its member countries (for details, see https://www.cabi.org/what-we-do/ how-we-work/cabi-donors-and-partners/). This contribution is an expansion on a workshop summarized in the proceedings of the XVth international symposium on the biological control of weeds, 26-31 August 2018, Engelberg, Switzerland. Agriculture and Agri-Food Canada provided funds to allow open access to this contribution (AAFC 19-074).

\section{Compliance with ethical standards}

Conflict of interest The authors declare that to the best of their knowledge there are no potential conflicts of interest. All authors have consented to submission of this manuscript.

Open Access This article is licensed under a Creative Commons Attribution 4.0 International License, which permits use, sharing, adaptation, distribution and reproduction in any medium or format, as long as you give appropriate credit to the original author(s) and the source, provide a link to the Creative Commons licence, and indicate if changes were made. The images or other third party material in this article are included in the article's Creative Commons licence, unless indicated otherwise in a credit line to the material. If material is not included in the article's Creative Commons licence and your intended use is not permitted by statutory regulation or exceeds the permitted use, you will need to obtain permission directly from the copyright holder. To view a copy of this licence, visit http://creativecommons.org/licenses/by/4.0/.

\section{References}

Alves RJ, 35 co-authors (2018) Brazilian legislation on genetic heritage harms biodiversity convention goals and threatens basic biology research and education. Ann Acad Bras Ciênc 90:1279-1284

Animal and Plant Health Inspection Service (APHIS), USDA (2019) Biological control organism permits. https://www. aphis.usda.gov/aphis/ourfocus/planthealth/importinformation/permits/regulated-organism-and-soil-permits/ biological-control-organism-permits. Accessed 10 July 2019

Briese DT (1997) Biological control of St. John's wort: past, present and future. Plant Prot Q 12:73-80

Briese DT (2000) Classical biological control. In: Sindel BM (ed) Australian weed management systems. RG and FJ Richardson, Melbourne, pp 161-192

Cock MJW, van Lenteren JC, Brodeur J, Barratt BIP, Bigler F, Bolckmans K, Cônsoli FL, Haas F, Mason PG, Parra JRP (2009) The use and exchange of biological control agents for food and agriculture. FAO background study paper No. 47. http://www.fao.org/tempref/docrep/fao/meeting/017/ ak569e.pdf. Accessed 23 July 2019

Cock MJW, van Lenteren JC, Brodeur J, Barratt BIP, Bigler F, Bolckmans K, Cônsoli FL, Haas F, Mason PG, Parra JRP (2010) Do new access and benefit sharing procedures under the convention on biological diversity threaten the future of biological control? BioControl 55:199-218 
Collis B (2000) The beetle that saved Lake Victoria. https:// www.abc.net.au/science/slab/hyacinth. Accessed 23 July 2019

Crouch NR, Douwes E, Wolfson MM, Smith GF, Edwards TJ (2008) South Africa's bioprospecting, access and benefit sharing legislation: current realities, future complications and a proposed alternative. S Afr J Sci 104:355-366

Department of Environmental Affairs (2012) South Africa's bioprospecting, access and benefit-sharing regulatory framework: guidelines for providers, users and regulators. https://www.environment.gov.za/sites/default/files/ legislations/bioprospecting_regulatory_framework_ guideline.pdf. Accessed 10 Mar 2019

Glowka L (2000) Bioprospecting, alien invasive species, and hydrothermal vents: Three emerging legal issues in the conservation and sustainable use of biodiversity. Tulane Environ Law J 13:329-360

Hinz H, Weyl P, Smith D, Djeddour D (2019) The Nagoya protocol: implications for classical biological control of invasive plant species. In: Hinz H, Bon M-C, Bourdôt G, Cristofaro M, Desurmont G, Kurose D, Müller-Schärer H, Rafter M, Schaffner U, Seier M, Sforza R, Smith L, Stutz S, Thomas S, Weyl P, Winston R (eds) Proceedings of the XV international symposium on biological control of weeds. Engelberg, Switzerland 26-31 August 2018, pp. 206-211

Julien MH (2006) Biological control of rangeland weeds in Australia. Rangeland J 28:47-54

Mason PG, Brodeur J (2013) Access and benefit-sharing and biological control. In: Mason PG, Gillespie DR (eds) Biological control programmes in Canada 2001-2012. CAB International Publishing, Wallingford, pp 6-11

Mason PG, De Clerck-Floate RA, Gallant B, Floate KD, Gillespie DR, Bourchier R, Douglas H, Vincent C, Boivin $G$ (2017) Guide for the first-time importation and release of arthropod biological control agents in Canada. AAFC Publication No. 12700E, Ottawa, Ontario, Canada

Mason PG, Bennett AMR, Fraleigh B (2018) Access to genetic resources and benefit-sharing affects entomology in Canada. Bull Entomol Soc Canada 50:120-126

Mc Kay F, Logarzo GA, Natale E, Sosa AJ, Cabrera Walsh GJ, Pratt PD, Sodergren C (2017) Feasibility assessment for the classical biological control of Tamarix in Argentina. BioControl 63:169-184

Neumann D, Borisenko AV, Coddington JA, Häuser LC, Butler RC, Casino A, Vogel JC, Haszprunar G, Giere P (2018) Global biodiversity research tied up by juridical interpretations of access and benefit sharing. Org Divers Evol 18:1-12

Page AR, Lacey K L (2006) Economic impact assessment of Australian weed biological control. Tech Ser No 10. CRC for Australian Weed Management, Adelaide

Pedrosa-Macedo JH (2000) Biology and behavior of the strawberry guava sawfly, Haplosteaus epimelas Konow 1901 (Hymenoptera: Pergidae), in the southern Brazil. Proc Entomol Soc Wash 102:129-134

Prathapan D, Pethiyagoda R, Bawa K, Raven P, Priyadarsanan D, 172 co-authors (2018) When the cure kills: CBD limits biodiversity research. Science 360:1405-1406

Schaffner U, Smith L, Cristofaro M (2018) A review of openfield host range testing to evaluate non-target use by herbivorous biological control candidates. BioControl 63:405-416

Schwarzländer M, Hinz HL, Winston RL, Day MA (2018) Biological control of weeds: an analysis of introductions, rates of establishment and estimates of success, worldwide. BioControl 63:319-331

ISSG (2018) The application of biological control for the management of established invasive alien species causing environmental impacts. Sheppard AW, Paynter Q, Mason P, Murphy S, Stoett P, Cowan P, Brodeur J, Warner K, Villegas C, Shaw R, Hinz H, Hill, M and Genovesi P (eds) Information document for the convention on biological diversity. IUCN SSC Invasive Species Specialist Group, pp. $1-88$

Silvestri L, Sosa A, Mc Kay F, Dino Vitorino M, Hill M, Zachariades C, Hight S (2019) The convention on biological diversity and the Nagoya protocol: implications for classical weed biological control. In: Hinz H, Bon M-C, Bourdôt G, Cristofaro M, Desurmont G, Kurose D, MüllerSchärer H, Rafter M, Schaffner U, Seier M, Sforza R, Smith L, Stutz S, Thomas S, Weyl P and Winston R (eds) Proceedings of the XV international symposium on biological control of weeds, Engelberg, Switzerland, 26-31 August 2018, pp. 304-309

Smith D, Hinz H, Mulema J, Weyl P, Ryan MJ (2018) Biological control and the Nagoya protocol on access and benefit sharing - a case of effective due diligence. Biocontrol Sci Technol 28:919-926

UN Environment World Conservation Monitoring Centre (UNWCMC) (2019) Megadiverse countries. https://www. biodiversitya-Z.org/content/megadiverse-countries. Accessed 28 March 2019

US Fish and Wildlife Service (USFWS) (2019) ECOS (Environmental Conservation Online System), conserving the nature of America. https://ecos.fws.gov/ecp/. Accessed 10 July 2019

van Driesche RG, Hoddle MS (2000) Classical arthropod biological control: measuring success, step by step. In: Gurr G, Wratten S (eds) Biological control: measures of success. Kluwer Academic Publishers, Dordrecht, pp 39-57

Winston RL, Schwarzländer M., Hinz HL, Day MD, Cock MJW, Julien MH (2014) Biological control of weeds: a world catalogue of agents and their target weeds, $5^{\text {th }}$ edition. The Forest Health Technology Enterprise Team, Morgantown, WV, FHTET-2014-04

Zachariades C (2018) Biological control of invasive alien plants in South Africa: a list of all insects, mites and pathogens considered as biological control agents from 1913-2018. https://www.arc.agric.za/arc-ppri/Documents/Table1NaturalEnemiesAll.pdf. Accessed 26 July 2019

Zachariades C, Paterson ID, Strathie LW, Hill M, van Wilgen BW (2017) Assessing the status of biological control as a management tool for suppression of invasive alien plants in South Africa. Bothalia 47:2142-2161

Luciana Silvestri is an environmental law researcher at the National Scientific and Technical Research Council (CONICET) in Argentina. She served as a legal and technical adviser to the Spanish Ministry of Environment, Rural and Marine Affairs for the Convention on Biological Diversity (CBD) 
issues and, in particular, for access and benefit-sharing (ABS) international negotiations. She was one of the legal experts contributing to the GEF UNEP IUCN Regional Project on ABS for Latin American and the Caribbean, where she focused on ensuring effective legal ABS frameworks and adequate institutional capacities in eight countries of the region (Colombia, Costa Rica, Cuba, the Dominican Republic, Ecuador, Guyana, Panama and Peru). She also served as an expert to the Informal Advisory Committee to the Access and Benefit-Sharing Clearing-House of the Nagoya Protocol. She has extensive expertise in international cooperation, international negotiations, biodiversity protection, access to genetic resources and equitable sharing.

Alejandro Sosa is a research scientist at Fundación para el Estudio de Especies Invasivas (FuEDEI) and Consejo Nacional de Investigaciones Científicas y Técnicas (CONICET) in Buenos Aires, Argentina. His research interests include measuring the impact of invasive alien plants, including biological control, climate change and social impact of invasive species.

Fernando Mc Kay is a researcher at the Fundación para el Estudio de Especies Invasivas (FuEDEI) in Buenos Aires, Argentina. He works on the ecology and classical biological control of invasive plants.

Marcelo Diniz Vitorino is a research scientist from the Forest Engineer Course - Blumenau University, Santa Catarina, Brazil and the coordinator from the Forest Protection Surveillance and Monitoring Laboratory. He conducts research on biological control of weeds, forest entomology and forest restoration. His work also supports the introduction of natural enemies against South American weeds spread all around the world.

Martin Hill is distinguished professor and head of entomology at Rhodes University, Grahamstown, South Africa. His research interests include the biological control of invasive alien aquatic weeds and insect pests, as well as the development of microbial agents for the control of pests in citrus and other crops.

Costas Zachariades is an entomologist, and a senior researcher at the Agricultural Research Council, South Africa. $\mathrm{He}$ is currently president of the IOBC Afrotropical Regional
Section. He has conducted research on the biological control of the plant Chromolaena odorata, invasive in many parts of the Old World tropics and subtropics, and is involved in research on several other invasive alien plant species, as well as legislative issues relevant to weed biocontrol.

Stephen Hight is a research scientist with the United States Department of Agriculture. His research focus is on developing and implementing biological control strategies against invasive insect and plant pests.

Philip Weyl is a research scientist with $\mathrm{CAB}$ International $(\mathrm{CABI})$. His research is focused on developing biological control agents for invasive weeds, including surveys, host range assessment and impact. He is also designated as CABI Switzerland Access and Benefit-Sharing officer to help guide staff in decisions around the acquisition of genetic resources.

David Smith is director of biological resources at $\mathrm{CAB}$ International. His research interests are in the conservation and sustainable use of microorganisms in agriculture and the environment with a key interest in microbial resource collection operation, management and technology. He currently leads a team of researchers in microbiology project development and is responsible for CABI's Nagoya Protocol access and benefitsharing policy and compliance.

Djami Djeddour is a senior invasive species scientist at CAB International, with over twenty one years of experience in developing, implementing and managing weed biocontrol and IPM projects for national and international sponsors/stakeholders. Her research has included a broad range of temperate and tropical weed targets and consequently she has had firsthand experience of the regulatory demands surrounding Access and Benefit-Sharing and their associated impact on biocontrol practitioners.

Peter G. Mason is a research scientist with Agriculture and Agri-Food Canada and current chair of the IOBC Global Commission on Access and Benefit-Sharing. He conducts research on importation biological control and risk assessment to provide biologically based solutions for pest problems in agroecosystems. His work also supports science-based decision making by regulators. 